\title{
BEARING CAPACITY OF STEEL I-SECTIONS UNDER COMBINED BENDING AND TORSION ACTIONS TAKING INTO ACCOUNT PLASTIC DEFORMATIONS
}

\author{
Aleksandr Romanovich Tusnin* \\ Moscow State University of Civil Engineering (MGSU), Russia \\ Milan Prokić \\ Moscow State University of Civil Engineering (MGSU), Russia
}

\begin{abstract}
In steel structures, the I-beams are in many cases exposed to combination of bending moment and bimoment actions. In the elastic stage of work, material strength check is based on maximum normal stresses, which for symmetric l-beams are the sum of moment and bimoment stresses. The maximum stresses are compared with calculated resistance. In both European codes and Russian standards for design of steel structures, calculation of members is performed considering the conditions in which the plastic deformations over the section are allowed. With the development of plastic strains, bearing capacity of section is higher than in the elastic stage. The existing normative documents for the design of steel structures in Russia do not include design coefficient taking into account development of plastic deformations in warping torsion. The article examines combined action of bending moment and bimoment on I-beam profiles throughout the theoretical and numerical solutions. Recommendations for checking their bearing capacity in accordance to Russian standards are given, taking into account development plastic deformations.
\end{abstract}

Key words: Bearing capacity, Warping torsion, I-beams, Bending moment, Bimoment

\section{INTRODUCTION}

Behavior of symmetric I-beams under the action of bending moment is well studied, including the development of plastic deformations, up to the formation of plastic hinge. In construction standards recommendations for calculating I-section beam bearing capacity in bending are given, considering plastic deformations of steel [5]. Accounting of plastic deformations can increase bearing capacity of profile up to $19 \%$ :

$$
\frac{M}{c W_{n} R_{v} \gamma_{c}} \leq 1
$$

where $M$ - bending moment, $\mathrm{W}_{\mathrm{n}}$ - section modulus Net, $\mathrm{R}_{\mathrm{y}}$ - yield strength, $\gamma_{c^{-}}$working conditions factor, $\mathrm{c}$ - factors which take into account the development of plastic deformations in bending[. In thin-walled open-section members warping torsion is causing additional sectorial stresses. Sectorial stresses are equivalent to internal force - bimoment. Under the combined action of bending moment and bimoment, the transition to plastic stage of work occurs earlier, than in bending.
The purpose of studding combined bending and warping torsion actions including the development of plastic deformations - development of practical methods for calculating thin-walled open-section members in complex loading.

\section{LITERATURE REVIEW}

Non-uniform torsion of thin-walled open sections in an elastic range was studied by Vlasov V.Z., Bychkov D.V., Timoshenko S.P. and Gere J.M., and Wagner $\mathrm{H}$. $[04,14,20,21]$ by considering small angles of cross-section rotation. Experimental studies of I-sections in uniform torsion were carried out by Boulton N.S., Dinno K.S. and Gill S.S., and Farwell C.R. and Galambos T.W. and results shown that in elastic-plastic torsion, experimental torques were much higher than those predicted by theory $[03,06,08]$. Theoretical studies of plastic torsion collapse for cantilever in warping torsion were done by Dinno K.S. and Merchant $\mathrm{W}$. They proposed that bearing capacity of the rod in plastic stage can be determined separately for two components: a uniform and warping torsion, and then summarized together [07]. 
Vatin N.I., Airumyan E.L., Rybakov V.A. [02,13,18] on concrete examples have shown the inapplicability of plane-sections hypothesis when analyzing stress-strain state of thin-walled open section profile. The unclear accounting of bimoment as an additional force factor, present in the Russian construction norms, was also noted. Theoretical and experimental studies confirmed the importance of accounting bimoment as force factor, which contributes greatly to the normal stresses of structural elements [09,10,11,19].

Pi Y.L. and Trahair N.S. [12] studied the behavior of steel I-beams in warping torsion, and showed that loss of member bearing capacity is due to plastic collapse of flanges and at large angles of rotation appearing before the formation of plastic hinge in the beam.

Later experimental results [01] and numerical studies [15] have shown that strain-hardening and second order longitudinal stresses cause significant strengthening at a large rotations.

Trahair N.S. [16] used Merchant method of analyzing and developed equations for the uniform torsion plastic torques and plastic bimoment for I-sections.

Tusnin A.R. and Prokic M. [17] offered that calculation of I-sections should be performed in a plastic stage of work in a shape corresponding to Russian standards for design of steel structures, and gave expression for checking bearing capacity of I-section under the action of bimoment. The calculation is performed using a plastic shape factor, which takes into account plastic deformations in warping torsion.

\section{PROBLEM DEFINITION}

The article analyzes the stress-strain state of a symmetric I-section under bending moment and bimoment actions including development of plastic deformations. Analysis of stress-strain state is held for a number of I-sections, covering a wide range of sizes.

Relative deformations form bending moment are linearly distributed over the cross section, and from action of bimoment - proportional to sectorial areas. It is assumed that plastic deformations can grow indefinitely over the cross section, while stresses are limited by yield strength. Theoretical relationships for ultimate bimoment depending on the bending moment are given.

To verify the theoretical dependences and practical formula, numerical studies based on physical nonlinearity of system are performed.

\section{DESCRIPTION OF THE RESEARCH}

Consider the strain and stress distribution over the cross section of a symmetric I-beam (Figure 1). Strain diagrams on height of the cross section and width of flanges do not change qualitatively with increasing load (diagram $\varepsilon_{\omega}$ - from bimoment and diagram $\varepsilon_{u}$ - from bending moment). Normal stresses are determined by deformations considering stress-strain diagram for steel. In the analysis of bearing capacity the absence of strain-hardening was accepted, thus yield area is considered to be infinite. Figure 1 shows diagrams of normal stresses, given for the state corresponding to the ultimate bearing capacity of profile. Feature of the stress distribution over the cross section is the balance between normal stresses and internal forces in the rod. Taking this into account, central zone of diagram (width "a" on flanges with oblique hatching) balances the bending moment $\mathrm{M}$, the side areas of diagram with straight hatching are balancing bimoment B.

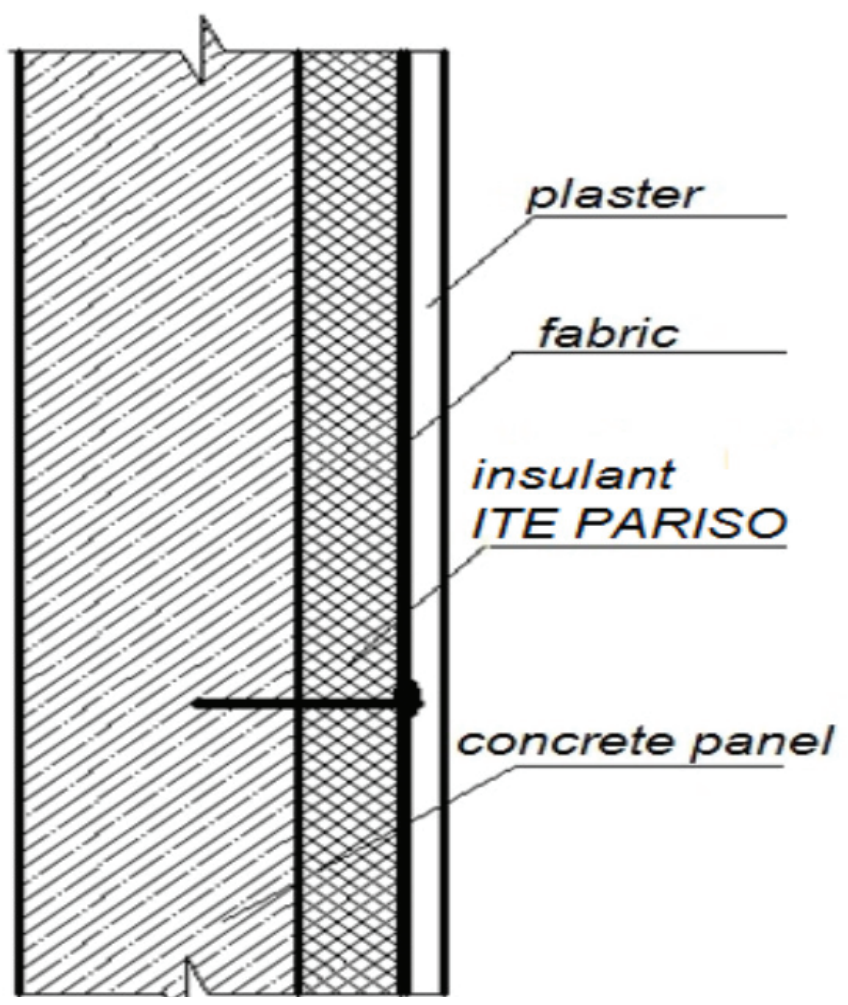

Figure 1: Stress-strain state of I-section under the combined action of bending moment about the $X$ axis and bimoment

Width on normal stress diagram is easy to determine from equality of external $M$ and internal $M_{\text {int }}$ bending moments: $M=M_{\text {int }}$ 
Considering that

$M_{\mathrm{int}}=h t_{f} a \sigma_{y}+\frac{A_{w}}{2} \frac{h}{2} \sigma_{y}$

where $\sigma_{y}$ - yield stress, $\mathrm{A}_{\mathrm{w}}=\mathrm{h}_{\mathrm{w}} \mathrm{t}$ - wall area, the width $a$ is equal:

$$
a=\frac{M-A_{w} h \sigma_{y} / 4}{t_{f} \sigma_{y} h}=\frac{M}{t_{f} \sigma_{y} h}-\frac{A_{w}}{4 t_{f}}
$$

Bimoment resisted by the section is:

$$
B / B_{p l}=\left(R_{y} \gamma_{c}-\frac{M}{c W_{n}}\right) c_{\omega} W_{\omega n} / B_{p l}
$$

where $\mathrm{c}=\left(\mathrm{b}_{\mathrm{f}}-a\right) / 2$, Substituting value $a$ defined above in the formula for $c$, and equating external bimoment with internal we obtain:

$$
B=0.5\left(A_{f} \sigma_{y}-\frac{M}{h}+\frac{A_{w} \sigma_{y}}{4}\right)\left(\frac{b_{f} h}{2}-\frac{M}{2 t_{f} \sigma_{y}}+\frac{A_{w} h}{8 t_{f}}\right) \text { (1) }
$$

Analysis of expression (1) shown, that ultimate bimoment depends on the value of bending moment acting in conjunction with bimoment. Ultimate bending moment can be obtained by using the procedure from construction norms:

$M_{p l}=c W_{n} \sigma_{y} \gamma_{c}$ where the coefficient $c$ is determined by the current regulations. Similarly, ultimate bimoment is given by:

$B_{p l}=c_{\omega} W_{\omega n} \sigma_{y} \gamma_{c}$ where $c_{\omega}=1.47$.

When checking safety of members under combined bending moment and bimoment actions, including plastic deformations, it is necessary to consider impact on the carrying capacity of both internal forces. Table 1 shows results of calculations, where relations of ultimate bimoment to plastic bimoment are depending on the ratio of acting moment to a plastic moment. Two schemes for determining required ratio were given:
- $1^{\text {st }}$ scheme: from condition $\frac{M}{c W_{n}}+\frac{B}{c_{\omega} W_{\omega n}}=R_{y} \gamma_{c}$ whence $B / B_{p l}=\left(R_{y} \gamma_{c}-\frac{M}{c W_{n}}\right) c_{\omega} W_{\omega n} / B_{p l}$

- $2^{\text {nd }}$ scheme: bimoment is determined by expression (1), which is modified given the fact that in RF norms development of plastic deformations in cross-section is limited. Therefore, in the region of neutral axis the elastic core is preserved, and bimoment is defined by:

$B=0.5\left(A_{f} R_{y}-\frac{M}{h}+\frac{M_{w p l}}{h}\right)\left(\frac{b_{f} h}{2}-\frac{M}{2 t_{f} R_{y}}+\frac{M_{w p l}}{2 t_{f} R_{y}}\right)$

where $M_{w p l}=M_{p l}-A_{f} R_{y} h$ - moment resisted by wall with the development of plastic deformations and $a>t_{w}$. In the schemes above, $R_{y}$ - design resistance by yield criterion.

In the first scheme calculations, ratio $B / B_{p l}$ varies linearly with $M / M_{p l}$. In the second scheme calculations relationship is non-linear, at the same time bimoment value is noticeably higher than in the first scheme. The variation of ratio $\left(B / B_{p}\right)$ with $\left(M / M_{p l}\right)$ is shown in Figure 2.

To assess the reliability of theoretical relationships, numerical studies of I-section profiles were performed. Calculations were carried out using computer program Nastran, for the section type 5, having by the second scheme minimal ultimate bimoment values compared to other sections. In numerical studies $5 \mathrm{~m}$ long cantilever was calculated, which was modeled by shell finite elements. The rod is divided into 250 elements in length, 10 elements in width and 20 elements in height. At one end rod is rigidly fixed, while at the free end of cantilever a concentrated load was applied. Forces equivalent to plastic bending moment and bimoment, were applied to wall and flange nodes. Two loads were considered: 1- moment, 2- bimoment.

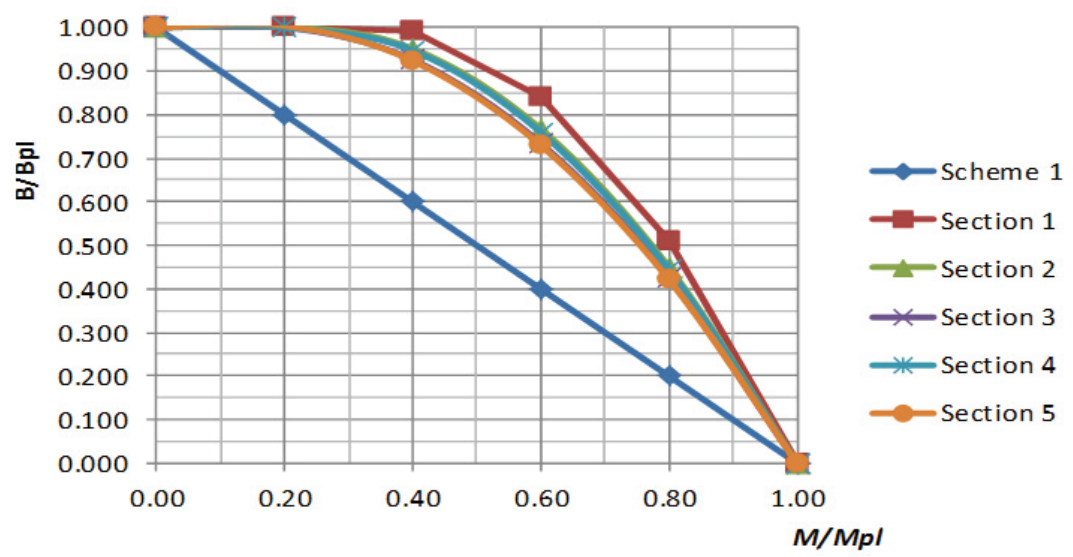

Figure 2: The variation of ratio $B / B_{p l}$ with $M / M_{p l}$ 
Table 1: Calculation of the combined moment and bimoment actions

\begin{tabular}{|c|c|c|c|c|c|}
\hline Section type & 1 & 2 & 3 & 4 & 5 \\
\hline$h_{w}, c m$ & 40,00 & 50,00 & 50,00 & 75,00 & 80,00 \\
\hline$t_{w}, c m$ & 0,80 & 0,60 & 0,60 & 0,80 & 1,00 \\
\hline$b_{f}, c m$ & 10,00 & 14,00 & 16,00 & 25,00 & 40,00 \\
\hline$t_{f}, c m$ & 1,4 & 1,6 & 1,8 & 2,0 & 2,2 \\
\hline $\mathrm{h}, \mathrm{cm}$ & 41,4 & 51,6 & 51,8 & 77,0 & 82,2 \\
\hline$A_{w}, \mathrm{~cm}^{2}$ & 32,0 & 30,0 & 30,0 & 60,0 & 80,0 \\
\hline$A_{f}, \mathrm{~cm}^{2}$ & 14,0 & 22,4 & 28,8 & 50,0 & 88,0 \\
\hline $\mathrm{I}_{\mathrm{t}}, \mathrm{cm}^{4}$ & 30,1 & 50,2 & 79,0 & 175,4 & 372,7 \\
\hline $\mathrm{I}_{\mathrm{w}}, \mathrm{cm}^{6}$ & 99981 & 487071 & 824291 & 7720052 & 39640128 \\
\hline $\mathbf{W}, \mathrm{cm}^{3}$ & 760,0 & 1356,0 & 1674,9 & 4464,6 & 8056,1 \\
\hline $\mathrm{W}_{\mathrm{w}}, \mathrm{cm}^{4}$ & 982,6 & 2739,4 & 4048,6 & 16252,7 & 48878,1 \\
\hline$G_{I^{\prime}}, K N / m^{2}$ & 23,512 & 39,152 & 61,596 & 136,781 & 290,734 \\
\hline$E_{l w^{\prime}}, K N / m^{4}$ & 20,596 & 100,337 & 169,804 & 1590,331 & 8165,866 \\
\hline$k$ & 1,068 & 0,625 & 0,602 & 0,293 & 0,189 \\
\hline $\mathrm{R}_{\mathrm{y}, \mathrm{kN} / \mathrm{cm}^{2}}$ & 24,0 & 24,0 & 24,0 & 24,0 & 24,0 \\
\hline$A_{f} / A_{w}$ & 0,438 & 0,747 & 0,960 & 0,833 & 1,100 \\
\hline c & 1,138 & 1,095 & 1,074 & 1,087 & 1,067 \\
\hline $\mathrm{cw}$ & 1,470 & 1,470 & 1,470 & 1,470 & 1,470 \\
\hline $\mathrm{M}_{\mathrm{pl}}, \mathrm{KN} \cdot \mathrm{m}$ & 207,48 & 356,48 & 431,74 & 1164,36 & 2063,01 \\
\hline$M_{w p l}, K N \cdot m$ & 68,38 & 79,07 & 73,69 & 240,36 & 326,94 \\
\hline $\mathrm{B}_{\mathrm{pl}}, \mathrm{KN} \cdot \mathrm{m}^{2}$ & 3,47 & 9,66 & 14,28 & 57,34 & 172,44 \\
\hline \multicolumn{6}{|c|}{ Calculation of $1^{\text {st }}$ scheme } \\
\hline $\mathrm{B} / \mathrm{B}_{\mathrm{pl}}$ at moment 0 & 1,000 & 1,000 & 1,000 & 1,000 & 1,000 \\
\hline $\mathrm{B} / \mathrm{B}_{\mathrm{pl}}$ at moment $0.2 \mathrm{M}_{\mathrm{pl}}$ & 0,800 & 0,800 & 0,800 & 0,800 & 0,800 \\
\hline $\mathrm{B} / \mathrm{B}_{\mathrm{pl}}$ at moment $0.4 \mathrm{M}_{\mathrm{pl}}$ & 0,600 & 0,600 & 0,600 & 0,600 & 0,600 \\
\hline $\mathrm{B} / \mathrm{B}_{\mathrm{pl}}$ at moment $0.6 \mathrm{M}_{\mathrm{pl}}$ & 0,400 & 0,400 & 0,400 & 0,400 & 0,400 \\
\hline $\mathrm{B} / \mathrm{B}_{\mathrm{pl}}$ at moment $0.8 \mathrm{M}_{\mathrm{pl}}$ & 0,200 & 0,200 & 0,200 & 0,200 & 0,200 \\
\hline $\mathrm{B} / \mathrm{B}_{\mathrm{pl}}$ at moment $\mathrm{M}_{\mathrm{pl}}$ & 0,000 & 0,000 & 0,000 & 0,000 & 0,000 \\
\hline \multicolumn{6}{|c|}{ Calculation of $2^{\text {nd }}$ scheme } \\
\hline $\mathrm{B} / \mathrm{B}_{\mathrm{pl}}$ at moment 0 & 1,000 & 1,000 & 1,000 & 1,000 & 1,000 \\
\hline $\mathrm{B} / \mathrm{B}_{\mathrm{pl}}$ at moment $0.2 \mathrm{M}_{\mathrm{pl}}$ & 1,000 & 1,004 & 1,001 & 1,000 & 1,004 \\
\hline $\mathrm{B} / \mathrm{B}_{\mathrm{pl}}$ at moment $0.4 \mathrm{M}_{\mathrm{pl}}$ & 0,992 & 0,952 & 0,926 & 0,947 & 0,924 \\
\hline $\mathrm{B} / \mathrm{B}_{\mathrm{pl}}$ at moment $0.6 \mathrm{M}_{\mathrm{pl}}$ & 0,840 & 0,767 & 0,734 & 0,759 & 0,730 \\
\hline $\mathrm{B} / \mathrm{B}_{\mathrm{pl}}$ at moment $0.8 \mathrm{M}_{\mathrm{pl}}$ & 0,509 & 0,450 & 0,425 & 0,444 & 0,422 \\
\hline$B / B_{p l}$ at moment $M_{p l}$ & 0,000 & 0,000 & 0,000 & 0,000 & 0,000 \\
\hline
\end{tabular}


Values of concentrated forces are defined in Table 2. Calculations were performed for load combinations, including share of 1 to 0 for $1^{\text {st }}$ and $2^{\text {nd }}$ loadings. In $1^{\text {st }}$ load concentrated forces were applied to all nodes of wall and flange, except to the neutral axis node, where two equal magnitude but oppositely directed forces are acting. In $2^{\text {nd }}$ load, forces are compensated at the junction point of wall and flange. On the loaded end, a cross stiffener with $6 \mathrm{~mm}$ thickness is provided, which eliminates distortion of section contour.

Figure 3 shows the calculation scheme of cantilever. In numerical studies both geometrical and physical nonlinearity of system was taken into account.

Table 2: Concentrated forces on nodes of wall and flanges

\begin{tabular}{|c|c|c|}
\hline \multirow{2}{*}{ Parameter } & \multicolumn{2}{|c|}{ Section 5} \\
\cline { 2 - 3 } & $\mathrm{M}_{\mathrm{pl}}, \mathrm{KN} \mathrm{m}$ & $\mathrm{B}_{\mathrm{p},}, \mathrm{KN} \mathrm{m}^{2}$ \\
\hline Complete value & 2063,00 & 172,44 \\
\hline $\mathrm{h}, \mathrm{cm}$ & 82,200 & 82,200 \\
\hline $\mathrm{b}, \mathrm{cm}$ & 40,000 & 40,000 \\
\hline $\mathrm{t}_{\mathrm{w}}, \mathrm{cm}$ & 1,000 & 1,000 \\
\hline $\mathrm{t}_{\mathrm{f}}, \mathrm{cm}$ & 2,200 & 2,200 \\
\hline $\mathrm{R}_{\mathrm{v}}, \mathrm{KN} / \mathrm{cm}^{2}$ & 24,000 & 24,000 \\
\hline Number of flenge nodes & 11 & 11 \\
\hline Force on the middle node of flenge, $\mathrm{KN}$ & 211,20 & 209,78 \\
\hline Force on the end nodes of flange, $\mathrm{KN}$ & 105,60 & 104,89 \\
\hline Moment resisted by wall, $\mathrm{KN} \mathrm{m}$ & 326,94 & \\
\hline Number of wall nodes & 21 & 21 \\
\hline Force on the middle node of wall, $\mathrm{KN}$ & 19,89 & \\
\hline Force on the end nodes of wall, $\mathrm{KN}$ & 29,83 & \\
\hline \multicolumn{2}{|l|}{} \\
\hline
\end{tabular}

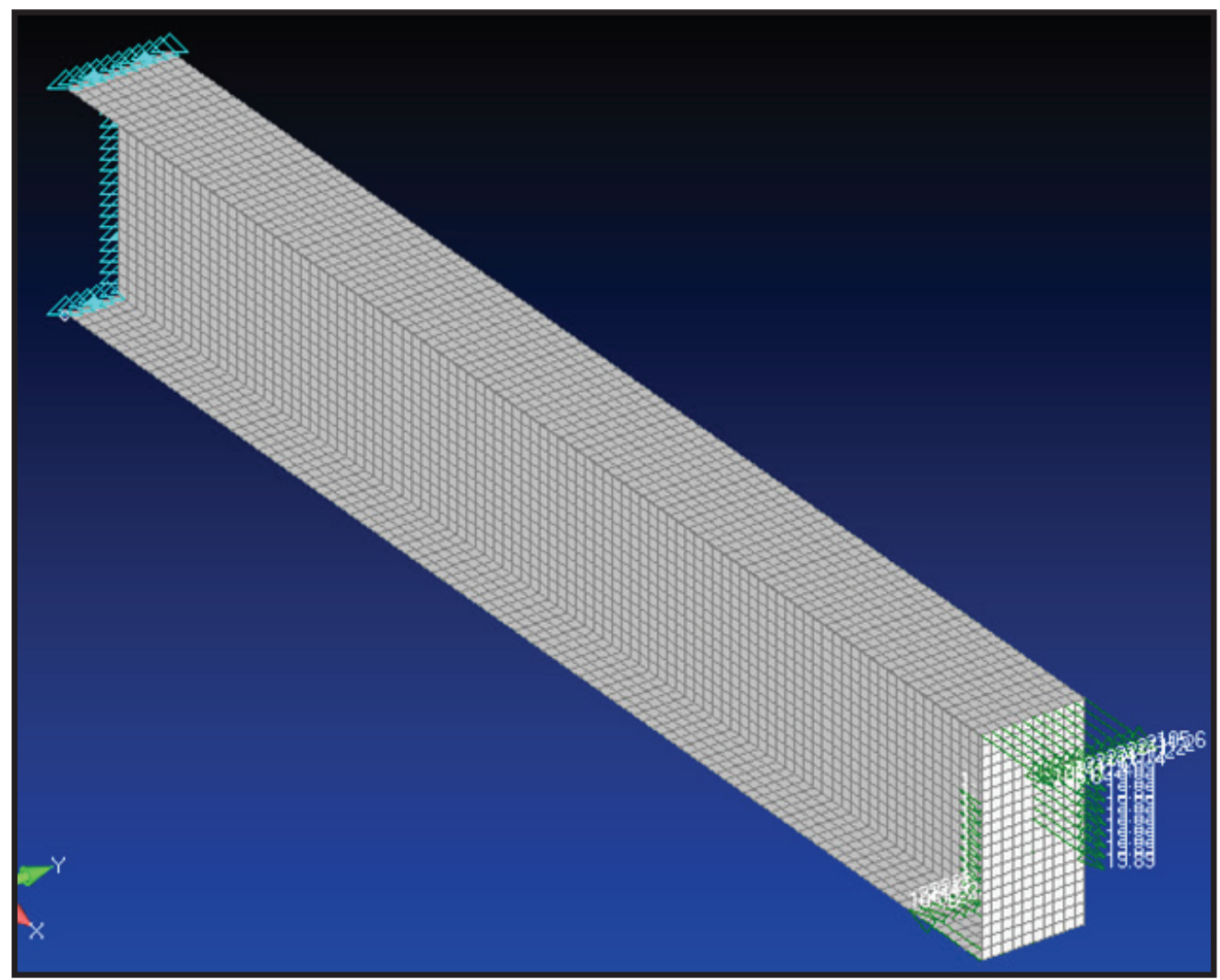

Figure 3: Computational scheme of cantilever under bending moment 
Figure 4 shows the stress-strain relationship:

- for stresses up to yield strength, equal to $240 \mathrm{MPa}$, dependence is linear with an elastic modulus $206000 \mathrm{MPa}$;

- further nearly horizontal line with a slight increase up to $250 \mathrm{MPa}$ at relative strain of 0.3 .

For each scheme of combined moment and bi- moment actions, nonlinear analysis was carried out as long as rod kept its bearing capacity.

In the first stage following combinations of moment. Normal stresses distribution at combined action of moment, equal to 0.4 from the plastic moment and bimoment equal to 0.6 from the plastic bimoment, is shown in Figure 5.

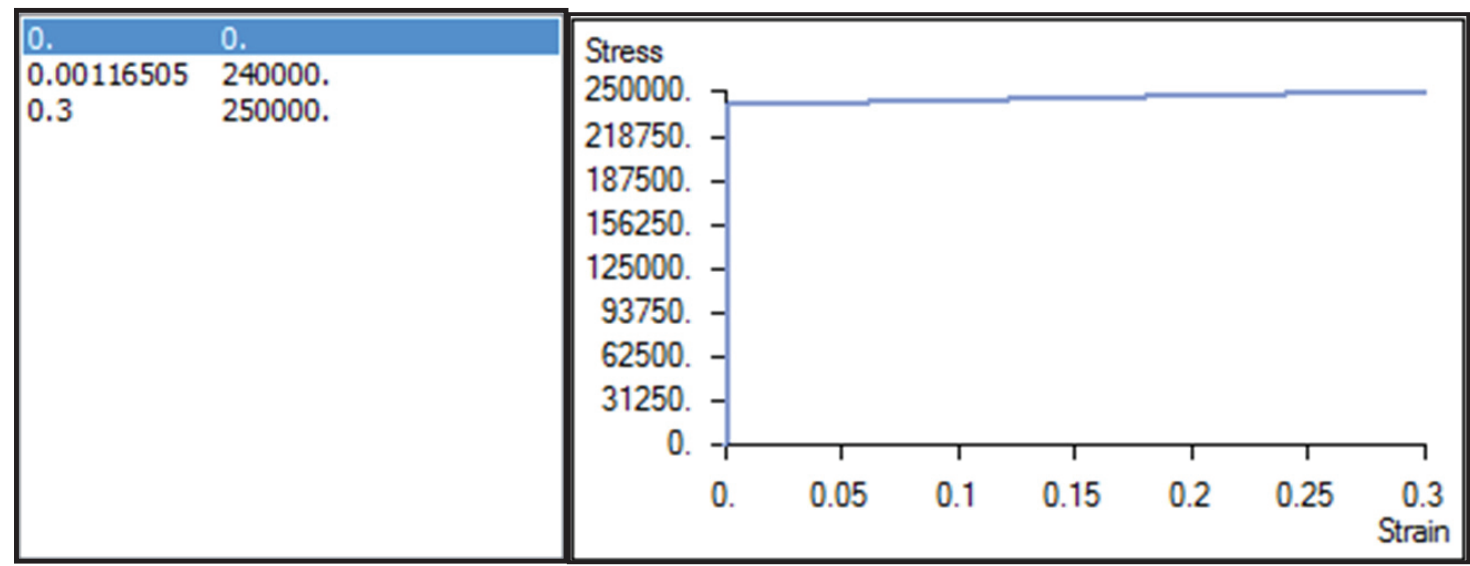

Figure 4: Relationship between stresses and strains

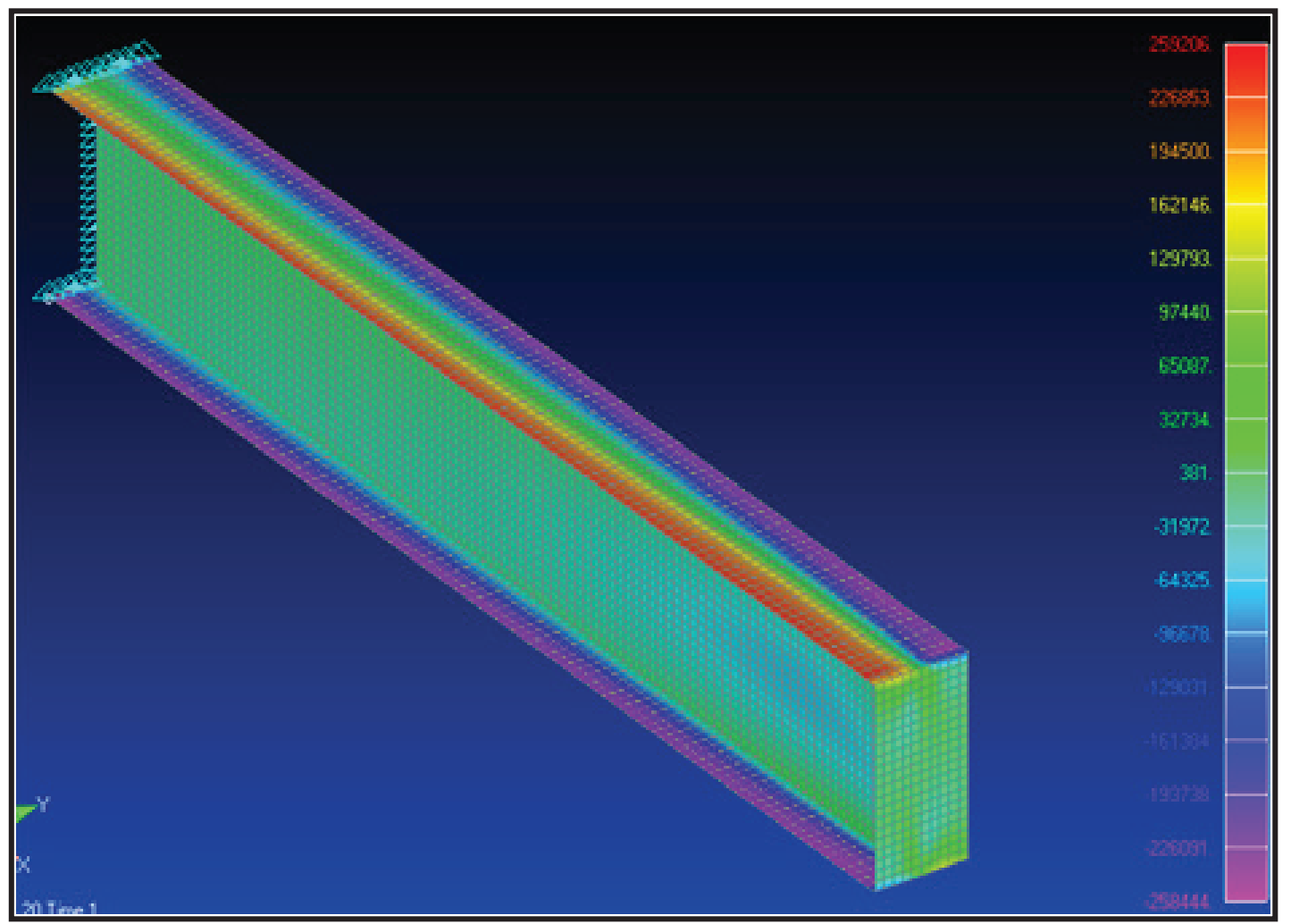

Figure 5: The distribution of normal stresses over the section at $M=0.4 M_{p l}$ and $B=0.6 B_{p l}$ 
For each scheme of combined moment and bimoment actions, nonlinear analysis was carried out as long as rod kept its bearing capacity. In the first stage following combinations of moment and bimoment actions were included:

- 1 combination: $M=0$ and $B=B_{p l}$;

- 2 combination: $M=0.2 M_{p l}$ and $B=0.8 B_{p l}$;

- 3 combination: $M=0.4 M_{p l}$ and $B=0.6 B_{p l}$;

- 4 combination: $M=0.6 M_{p l}$ and $B=0.4 B_{p l}$;

- 5 combination: $M=0.8 M_{p l}$ and $B=0.2 B_{p l}$;

- 6 combination: $M=M_{p l}$ and $B=0$.

Calculations shown that in 3, 4 and 5 combination, difference between the ultimate load (consisting of the bending moment acting jointly with bimoment) and applied load was reaching $14 \%$.

At the second stage bimoment value was adjusted so that bearing capacity was provided at full load for each of the combinations. Relations of internal forces, obtained by different methods, which ensured bearing capacity, are shown in Table 3 .

Table 3: Relations of internal forces which ensured bearing capacity

\begin{tabular}{|c|c|c|c|}
\hline \multirow{2}{*}{$\mathrm{M}_{\mathrm{N}} \mathrm{M}_{\mathrm{pl}}$} & \multicolumn{3}{|c|}{$\mathrm{B} / \mathrm{B}_{\mathrm{pl}}$} \\
\cline { 2 - 4 } & $\begin{array}{c}1^{\text {st }} \text { option } \\
\text { Table 2 }\end{array}$ & $\begin{array}{c}2^{\text {nd }} \text { option } \\
\text { Table 2 }\end{array}$ & $\begin{array}{c}\text { The } \\
\text { numerical } \\
\text { calculation }\end{array}$ \\
\hline 0 & 1,000 & 1,000 & 1,000 \\
\hline 0,2 & 0,800 & 1,004 & 0,800 \\
\hline 0,4 & 0,600 & 0,924 & 0,400 \\
\hline 0,6 & 0,400 & 0,730 & 0,260 \\
\hline 0,8 & 0,200 & 0,422 & 0,100 \\
\hline 1 & 0,000 & 0,000 & 0,000 \\
\hline
\end{tabular}

Analysis of numerical results showed that the bearing capacity of I-section profile, taking into account the development of plastic deformations, is significantly less than the bearing capacity obtained, both theoretically (option 2), and using the procedure similar to normative (option 1:

$\left.\frac{M}{c W_{n}}+\frac{B}{c_{\omega} W_{\omega n}} \leq R_{y} \gamma_{c}\right)$

, where the coefficients $c$ and $c_{\omega}$ depend only on the parameters of section. In view of this, for practical calculations regulatory procedure needs to be clarified. Studies found that in bearing capacity check, a coefficient $c$ needs to be changed over the entire range of $M$ and $B$ and assigned to the accordance with regulations for design of steel structures. Coefficient $C_{\omega}$ should be changed when changing the ratio of $M / M_{p l}$. Table 4 describes the recommended values of coefficient $c_{\omega}$.

Table 4: Recommended values of $C_{\omega}$

\begin{tabular}{|c|c|}
\hline $\mathrm{M} / \mathrm{M}_{\mathrm{pl}}$ & $\mathrm{B} / \mathrm{B}_{\mathrm{pl}}$ \\
\hline 0 & 1,470 \\
\hline 0,2 & 1,470 \\
\hline 0,4 & 1,176 \\
\hline 0,6 & 0,956 \\
\hline 0,8 & 0,833 \\
\hline 0,9 & 0,588 \\
\hline 1 & 0,588 \\
\hline
\end{tabular}

Intermediate values of coefficient $c_{\omega}$ are determined by linear interpolation. Final check of symmetric I-section profile bearing capacity will be carried out according to formula:

$$
\frac{M}{c W_{n} R_{y} \gamma_{c}}+\frac{B}{c_{\omega} W_{\omega n} R_{y} \gamma_{c}} \leq 1
$$

where the coefficient $c$ is determined by the current regulations, coefficient $c_{\omega}$ - by Table 4 .

\section{CONCLUSION}

Analysis of symmetrical I-beam loaded with bending moment and bimoment, allowed to establish laws of cross section transition from elastic to a plastic phase of work and examine the limit bearing capacity. Numerical calculations revealed, that with the growth of bending moment bearing capacity decreases faster than in the theoretical studies. An engineering method was given, allowing to check the bearing capacity of symmetric I-beam under combined action of moment and bimoment.

\section{REFERENCES}

1) Aalberg, A., (1995) An experimental study of beam-columns subjected to combined torsion, bending, and axial actions, Dr.ing. thesis, Trondheim: Department of Civil Engineering, Norwegian institute of Technology

2) Airumyan, E.L., (2008) Osobennosti rascheta konstruktsiy iz tonkostennykh gnutykh profiley, Montazhnye i spetsial'nye raboty $\mathrm{v}$ stroitel'stve, (3), 2-7

3) Boulton, N.S., (1962) Plastic twisting and bending of an I-section in which warp is restricted, Int. J. Mech. Sci., 4, 491-502 
4) Bychkov, D.V., (1962) Stroitel'naya mekhanika sterzhnevykh tonkostennykh konstruktsiy [Structural mechanics of bar thin-walled systems], Moscow: Gosstroyizdat Publ., 475

5) Code of rules (2011) SP 16.13330.2011 Steel structures, Updated version SNIP II-23-81*, Moscow: Ministry of Regional Development of the Russian Federation, 172

6) Dinno, K.S., and Gill, S.S., (1964) The plastic torsion of I-sections with warping restraint, Int. J. Mech. Sci., 6, 27-43

7) Dinno, K.S., and Merchant, W., (1965) A procedure for calculating the plastic collapse of I-sections under bending and torsion, The Struct. Engr., 43(7), 219-221

8) Farwell Jr., C.R., Galambos, T.V., (1969) Nonuniform torsion of steel beams in elastic range, J. Struct. Div., 95(12), 2813-2829

9) Heinisuo, M., Kukkonen, J., (2006) Resistance of cold-formed steel members by new eurostandard, Structural Mechanics, 39(2), 3-21

10) Lalin, V.V., Rybakov, V.A., Morozov, S.A., (2012) The Finite Elements Research for Calculation of Thin-Walled Bar Systems, Magazine of Civil Engineering, (1), 53-73

11) Nazmeeva, T.V., (2013) Bearing capacity of compressed continuous and perforated thin-walled steel members of C-shaped cold-formed profiles, Magazine of Civil Engineering, (5), 44-51

12) Pi, Y.L., and Trahair, N.S., (1995) Inelastic torsion of steel I-beams, Journal of Structural Engineering, 121(4), 609-620

13) Rybakov, V.A., Gamayunova, O.S., (2013) The stress-strain state of frame constructions' elements from thin-walled cores, Internet Journal "Construction of Unique Buildings and Structures", 7(12), 79-123
14) Timoshenko, S.P., Gere, J.M., (1961) Theory of elastic stability, New York: McGraw-Hill, 541

15) Trahair, N.S., (2005) Non-linear elastic nonuniform torsion, Journal of Structural Engineering, 131(7), 1135-1142

16) Trahair, N.S., (1999) Plastic torsion analysis of monosymmetric and point-symmetric beams, Journal of Structural Engineering, 125(2), 175-182

17) Tusnin, A.R., Prokic M., (2014) Resistance of I-beams in warping torsion with account for the development of plastic deformations, Vestnik MGSU [Proceedings of Moscow State University of Civil Engineering], (1), 75-82

18) Vatin, N.I., Nazmeeva, T.V., Guslinscky, R., (2014) Problems of cold-bent notched cshaped profile members, Advanced Materials Research, Vols. 941-944, 1871-1875

19) Vatin, N.I., Havula, J., Martikainen, L., Sinelnikov, A., Orlova, A., Salamakhin, S., (2014) Thin-walled cross-sections and their joints: tests and FEM-modelling, Advanced Materials Research, Vols. 945-949,1211-1215

20) Vlasov, V.Z., (1959) Tonkostennye uprugie sterzhni [Thin-walled Elastic Beams], Moscow: Fizmatgiz Publ, 568

21) Wagner, $H_{\text {., }}$ (1936) Verdrehung und Knickung von offenen Profilen, NACA Tech. Memo. No. 807, Washington D.C.

Paper sent to revision: 31.03.2014.

Paper ready for publication: 12.09.2014. 